\title{
Experimental Study on Construction Waste Making New Road Brick with Recycled Aggregate Concrete
}

\author{
Yang Jinglin, Tang Feng ", Wan Linhui, Fang Liang, Ou Yangguoyuan \\ College of Engineering, Hunan Agriculture University, Changsha, China
}

\section{Email address:}

yangj1@hunau.edu.cn (Tang Feng)

${ }^{*}$ Corresponding author

\section{To cite this article:}

Yang Jinglin, Tang Feng, Wan Linhui, Fang Liang, Ou Yangguoyuan. Experimental Study on Construction Waste Making New Road Brick with Recycled Aggregate Concrete. Science Discovery. Vol. 5, No. 7, 2017, pp. 598-602. doi: 10.11648/j.sd.20170507.31

Received: November 13, 2017; Accepted: November 23, 2017; Published: December 29, 2017

\begin{abstract}
Pedestrian road paving brick is a kind of paving material. It is made of cement, stone and sand as raw material, and it is cut into stripes or squares by vibrating forming surface. According to the construction waste recycled aggregate concrete, the water cement ratio, recycled aggregate replacement rate as the main parameters, design a new type of plate nail experimental study on pedestrian road brick, road brick design has 4 panels and 6 plate nail nails, nail plate thickness were designed as $1 \mathrm{~mm}$, $1.5 \mathrm{~mm}$ and $2 \mathrm{~mm}$. The influence of different water binder ratio and recycled aggregate replacement rate on the compressive strength and skid strength of the new pavement brick was analyzed by orthogonal test. The experimental results show that the compressive strength and slip strength of the new type of pavement brick decrease with the replacement rate of recycled aggregate concrete gradually increasing. Nail type plate relative to the compressive strength of brick without road brick plate nail is similar, but the anti slip strength increased; the nail plate thickness on pavement brick tile anti sliding strength were improved, the total efficiency coefficient is similar.
\end{abstract}

Keyword: Construction Waste, Recycled Aggregate, Concrete, New Road Brick, Experiment, Strength

\section{建筑垃圾再生骨料混凝土制作新型路面砖试验研究}

杨敬林，汤峰"，万琳辉，方亮，欧阳国元

工学院, 湖南农业大学, 长沙, 中国

邮箱

yangj1@hunau.edu.cn（汤峰）

摘要: 人行道路面砖是一种铺地材料, 由水泥、石子、沙子做原料, 经震动成型表面切磨出条纹或方格。本文针对建 筑垃圾废弃混凝土再生骨料, 以水灰比、再生骨料替代率为主要参数, 设计制作一种新型的板钉式人行道路面砖进行 试验研究, 路面砖设计有 4 个板钉和 6 个板钉, 板钉厚度分别设计为 $1 \mathrm{~mm} 、 1.5 \mathrm{~mm}$ 和 $2 \mathrm{~mm}$ 。采用正交试验, 分析不同水 胶比和再生骨料替代率等因素对新型路面砖的抗压强度和抗滑移强度的影响。试验研究表明, 随再生骨料混凝土替代 率逐渐增大, 新型路面砖的抗压强度和抗滑移强度反而降低; 板钉式路面砖相对于没有设置板钉的路面砖抗压强度基 本相近, 但抗滑移强度有一定提高; 路面砖的板钉厚度对路面砖抗滑移强度也有一定的改善, 其总功效系数基本相近。

关键词：建筑垃圾, 再生骨料, 混凝土, 新型路面砖, 试验, 强度 


\section{1. 引言}

建筑业是社会发展的基础性行业, 最近十年来随着社 会经济的快速发展, 建筑业产生的建筑垃圾空前增加, 对 社会生态环境产生了很大危害。文献[1]介绍我国近几年每 年拆除的建筑垃圾超过 3 亿吨, 新建建筑产生建筑垃圾超 过 1 亿吨, 占人类生产活动产生固体废弃物总量的 $40 \%$ 。 建筑垃圾的大量排放将占用很多宝贵的土地资源, 造成严 重的环境污染, 生态也不断遭到破坏。如何将建筑垃圾变 废为宝, 对废弃混凝土进行合理有效的回收利用, 已成为 亟待解决的实际问题。在文献[2-3]反映目前我国建筑垃圾 废弃混凝土的利用率还不到 $5 \%$, 而在文献 [4]中日本等发 达国家建筑垃圾资源化利用率已达 $90 \%$ 以上。
如图1所示，建筑垃圾是指主要是由废旧混凝土土块、 废砖瓦、废砂浆、废沥青混凝土块和废金属等组成, 其中绝 大多数是废旧混凝土块。文献[5]将废弃混凝土块经过加工、 破碎、分级后, 按一定的比例混合形成再生骨料, 部分或全 部代替天然骨料 (主要是粗骨料) 配制而成的新混凝土称为 再生混凝土。本文借鉴文献[6-7]应用建筑垃圾再生混凝土再 生粗骨料替代天然粗骨料设计制作一种新型板钉式人行道 路面砖, 图2 所示路面砖底面设计 4 个板钉和 6 个板钉, 板钉 厚度分别设计为 $1 \mathrm{~mm} 、 1.5 \mathrm{~mm}$ 和 $2 \mathrm{~mm}$, 采用正交试验, 分析 不同水胶比和再生骨料替代率等因素对新型路面砖的抗压 强度和抗滑移强度的影响, 对再生混凝土的工作性能进行研 究, 探讨建筑垃圾可再生资源的应用可行性分析, 为再生骨 料和再生混凝土的应用提供有利的研究参考。

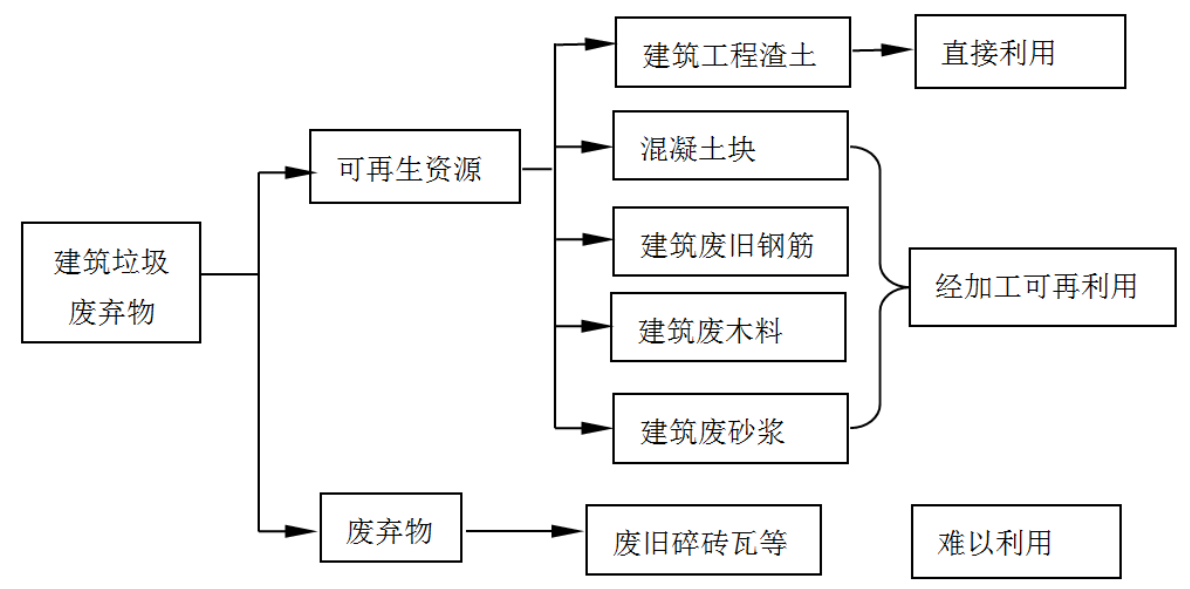

图1 建筑垃圾分类。

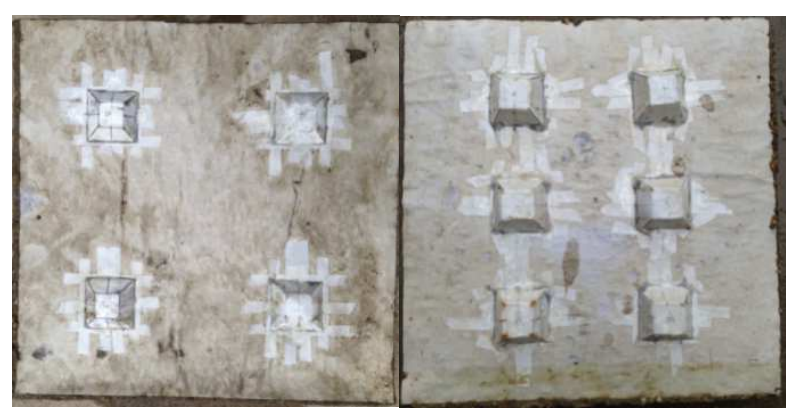

图2 一种新型板钉式路面砖底面。

\section{2. 试验原材料与试验设计}

试验用原材料水泥采用长沙坪塘水泥有限公司生产 的P.O32.5级普通硅酸盐水泥, 其物理力学性能参考文献[8] 见表1所示。

表1 水泥基本物理性质。

\begin{tabular}{lllllll}
\hline \multirow{2}{*}{ 项目 } & 凝结时间 & & \multicolumn{2}{l}{ 抗压强度 } & \multicolumn{2}{l}{ 抗折强度 } \\
\cline { 2 - 7 } & 初凝/ $/ \mathbf{m i n}$ & 终凝/h & $\mathbf{7 d}$ & $\mathbf{2 8 d}$ & $\mathbf{7 d}$ & $\mathbf{2 8 d}$ \\
\hline 测试数据 & 124 & 6.4 & 18.89 & 38.25 & 3.86 & 6.94 \\
\hline
\end{tabular}

天然砂采用粒径为 $0.16 \sim 5 \mathrm{~mm}$ 的普通河砂, 细度模数 2.8, 属于II区中砂。天然粗骨料采用天然我鸟卵石, 粒径5
$16 \mathrm{~mm}$, 再生骨料采用拆迁安置房建筑垃圾梁柱楼板废弃混 凝土, 在实验室经过人工重锤破碎并篮分后得到要求粒径, 其粗骨料颗粒级配见表2 所示。水直接取用长沙自来水。

表2 粗骨料颗粒级配。

\begin{tabular}{lllll}
\hline 粗骨料类型 & 粒径范围 $(\mathbf{m m})$ & 表观密度 $\left(\mathbf{k g} / \mathbf{m}^{3}\right)$ & 吸水率 $/ \%$ & 备注 \\
\hline 天然粗骨料 & $10 \sim 20$ & 2750 & 1.6 & \\
再生粗骨料 & $10 \sim 20$ & 2430 & 4.2 & \\
\hline
\end{tabular}

试验设计正交试验因素水平见表3所示。

表3 $\mathrm{L}_{9}\left(3^{4}\right)$ 因素水平表。

\begin{tabular}{llll}
\hline \multirow{2}{*}{ 水平 } & 因素 & & \\
\cline { 2 - 4 } & 再生骨料替代率 $\boldsymbol{t}_{\boldsymbol{i}}(\mathbf{\%})$ & 板钉数量 $($ 个) & 板钉高度 $(\mathbf{m m})$ \\
\hline 1 & 0 & 0 & 0 \\
2 & 50 & 4 & $1.0 / 1.5 / 2.0$ \\
3 & 75 & 6 & $1.0 / 1.5 / 2.0$ \\
\hline
\end{tabular}

本设计的再生混凝土配合比以普通混凝土配合比设计 准则为依据, 要求 $\mathrm{C} 25$ 混凝土配合比设计为 $\mathrm{C}: \mathrm{S}: \mathrm{G}=1$ : 2.17:3.84, $\mathrm{W} / \mathrm{C}=0.4$ 根据再生骨料取代天然骨料不同(替代率 分别为 $0,50 \%, 75 \%)$, 根据文献 $[9-10]$ 设计要求新拌混凝 土的坍落度不超过 $30 \mathrm{~mm}$, 并且尽量保证水泥用量, 满足水 灰比和再生混凝土的耐久性要求。各组混凝土拌和物均采 用HJW-30单卧轴强制式混凝土摚拌机机械摚拌, 具体做法 按 (GB/T 50080-2002) 进行, 每组试件置放振动台振动时 
间为 $10 \mathrm{~s}$, 每组混凝土共浇筑 $150 \mathrm{~mm} \times 150 \mathrm{~mm} \times 150 \mathrm{~mm}$ 立方 体试件 3 块, 共 9 大组 45 件标准试块(其中板钉数量为 4 个和 6 个在板钉厚度因素指标上每组试验只做了2块试件), 每组 所有试件均为一批浇注统一完成试件, 在浇筑24h后拆模, 在标准养护条件下养护至 $28 \mathrm{~d}$, 最后根据《混凝土路面砖》 （GB28635-2012）相关标准并参照文献[11-12]对养护好的 路面砖进行抗压强度和抗滑移强度测试。

\section{3. 试验结果和分析}

本文关于建筑垃圾再生骨料混凝土新型人行道路面 砖的正交试验应用功效系数法进行分析。为简化试验结 果, 每组试验的评价指标为总功效系数。假设正交试验 考核 $n$ 个指标, 第 $i$ 组试验每项指标经过归一化(每一表格 单项指标除以表中该单项指标之和)处理后的功效系数 为 $d_{i}, d_{i}$ 越接近 1 表示该组试验指标效果越好, 因此每组 试验的总功效系数可以定义为

$$
d_{i}=\sqrt[n]{d_{i 1} d_{i 2} d_{i 3} \cdots d_{i n}}
$$

本文正交试验总共9组27块试件，每组试验考核的指 标有 2 项, 即抗压强度和抗滑移强度, 试验结果经归一化 处理后, 功效系数分别为 $d_{1}$ 和 $d_{2}$, 则第 $i$ 组试验的总功效系 数为

$$
d_{i}=\sqrt{d_{i 1} d_{i 2}}
$$

总功效系数最大者表明综合性能最好。正交试验结果 及归一化处理见表4至表6所示。

\begin{tabular}{|c|c|c|c|c|c|c|}
\hline \multirow{2}{*}{$\begin{array}{l}\text { 组 } \\
\text { 组 } \\
\text { 名 }\end{array}$} & \multicolumn{3}{|c|}{ 抗压强度 } & \multicolumn{2}{|c|}{ 抗滑移强度 } & \multirow{2}{*}{$\begin{array}{l}\text { 总功效系 } \\
\text { 数 }\end{array}$} \\
\hline & 试件 & $\begin{array}{l}\text { 试验强度 } \\
\text { /(MPa) }\end{array}$ & 归一化 & $\begin{array}{l}\text { 试验强度 } \\
/(\mathbf{M P a})\end{array}$ & 归一化 & \\
\hline \multirow{3}{*}{1} & $1-1$ & 25.2 & 0.0717 & 2.8 & 0.0513 & 0.0606 \\
\hline & $1-2$ & 24.6 & 0.0700 & 2.9 & 0.0531 & 0.0610 \\
\hline & $1-3$ & 24.8 & 0.0706 & 1.7 & 0.03111 & 0.0469 \\
\hline \multirow{6}{*}{2} & $2-11$ & 18.8 & 0.0535 & 3.6 & 0.0659 & 0.0594 \\
\hline & $2-12$ & 24.3 & 0.0692 & 3.2 & 0.0586 & 0.0637 \\
\hline & $2-21$ & 26.8 & 0.0763 & 3.1 & 0.0568 & 0.0658 \\
\hline & $2-22$ & 23.4 & 0.0666 & 3.8 & 0.0696 & 0.0681 \\
\hline & $2-31$ & 25.8 & 0.0734 & 4.0 & 0.0733 & 0.0733 \\
\hline & $2-32$ & 24.7 & 0.0703 & 4.1 & 0.0751 & 0.0727 \\
\hline \multirow{6}{*}{3} & $3-11$ & 23.8 & 0.0677 & 4.3 & 0.0788 & 0.0730 \\
\hline & $3-12$ & 26.9 & 0.0766 & 3.9 & 0.0714 & 0.0739 \\
\hline & $3-21$ & 25.1 & 0.0714 & 4.5 & 0.0824 & 0.0767 \\
\hline & $3-22$ & 23.2 & 0.0660 & 4.3 & 0.0788 & 0.0721 \\
\hline & $3-31$ & 22.6 & 0.0643 & 4.6 & 0.0842 & 0.0736 \\
\hline & $3-32$ & 11.4 & 0.0324 & 3.8 & 0.0696 & 0.0475 \\
\hline
\end{tabular}

表4 试验结果归一化处理：前3组1-9试件试验统计 $(t=0 \%)$ 。

\begin{tabular}{|c|c|c|c|c|c|c|}
\hline \multirow{2}{*}{$\begin{array}{l}\text { 组 } \\
\text { 组 } \\
\text { 名 }\end{array}$} & \multirow[b]{2}{*}{ 试件 } & \multicolumn{2}{|l|}{ 抗压强度 } & \multicolumn{2}{|c|}{ 抗滑移强度 } & \multirow{2}{*}{$\begin{array}{l}\text { 总功效系 } \\
\text { 数 }\end{array}$} \\
\hline & & $\begin{array}{l}\text { 试验强度 } \\
\text { /(MPa) }\end{array}$ & 归一化 & $\begin{array}{l}\text { 试验强度 } \\
\text { /(MPa) }\end{array}$ & 归一化 & \\
\hline \multirow{3}{*}{4} & $4-1$ & 16.2 & 0.0834 & 1.2 & 0.0380 & 0.0563 \\
\hline & $4-2$ & 14.3 & 0.0736 & 1.1 & 0.0348 & 0.0506 \\
\hline & $4-3$ & 14.8 & 0.0762 & 0.8 & 0.0253 & 0.0439 \\
\hline \multirow{3}{*}{5} & $5-11$ & 15.8 & 0.0814 & 1.6 & 0.0506 & 0.0642 \\
\hline & $5-12$ & 14.9 & 0.0767 & 2.1 & 0.0665 & 0.0714 \\
\hline & $5-21$ & 12.1 & 0.0623 & 2.3 & 0.0728 & 0.0673 \\
\hline
\end{tabular}

表5 试验结果归一化处理: 中间3组10-18试件试验统计 $\left(t_{i}=50 \%\right)$ 。

\begin{tabular}{lllllll}
\hline 组 & & 抗压强度 & \multicolumn{3}{l}{ 抗滑移强度 } & 总功效系 \\
\cline { 1 - 1 } 组 & 试件 & $\begin{array}{l}\text { 试验强度 } \\
\text { 名 }\end{array}$ & 归一化 & $\begin{array}{l}\text { 试验强度 } \\
\text { /(MPa) }\end{array}$ & 归一化 & 数 \\
\hline & $5-22$ & 10.8 & 0.0556 & 1.9 & 0.0601 & 0.0578 \\
& $5-31$ & 12.1 & 0.0623 & 2.2 & 0.0696 & 0.0659 \\
& $5-32$ & 10.9 & 0.0561 & 2.4 & 0.0759 & 0.0653 \\
& $6-11$ & 10.8 & 0.0556 & 2.3 & 0.0728 & 0.0636 \\
& $6-12$ & 12.9 & 0.0664 & 2.5 & 0.0791 & 0.0725 \\
6 & $6-21$ & 13.4 & 0.0690 & 2.5 & 0.0791 & 0.0739 \\
& $6-22$ & 12.7 & 0.0654 & 2.9 & 0.0918 & 0.0775 \\
& $6-31$ & 9.4 & 0.0484 & 2.8 & 0.0886 & 0.0655 \\
& $6-32$ & 13.1 & 0.0675 & 3.0 & 0.0949 & 0.0800 \\
\hline
\end{tabular}

\begin{tabular}{|c|c|c|c|c|c|c|}
\hline \multirow{2}{*}{$\begin{array}{l}\text { 组 } \\
\text { 组 } \\
\text { 名 }\end{array}$} & \multicolumn{3}{|c|}{ 抗压强度 } & \multicolumn{2}{|c|}{ 抗滑移强度 } & \multirow{2}{*}{$\begin{array}{l}\text { 总功效 } \\
\text { 系数 }\end{array}$} \\
\hline & 试件 & $\begin{array}{l}\text { 试验强度 } \\
/(\mathbf{M P a})\end{array}$ & 归一化 & $\begin{array}{l}\text { 试验强度 } \\
\text { ((MPa) }\end{array}$ & 归一化 & \\
\hline \multirow{3}{*}{7} & $7-1$ & 12.1 & 0.0722 & 1.4 & 0.0543 & 0.0626 \\
\hline & $7-2$ & 10.1 & 0.0603 & 1.2 & 0.0465 & 0.0530 \\
\hline & $7-3$ & 10.3 & 0.0615 & 1.5 & 0.0581 & 0.0598 \\
\hline \multirow{6}{*}{8} & $8-11$ & 9.8 & 0.0585 & 1.6 & 0.0620 & 0.0602 \\
\hline & $8-12$ & 10.9 & 0.0651 & 1.8 & 0.0698 & 0.0674 \\
\hline & $8-21$ & 10.6 & 0.0633 & 1.5 & 0.0581 & 0.0607 \\
\hline & $8-22$ & 9.8 & 0.0585 & 1.9 & 0.0736 & 0.0656 \\
\hline & $8-31$ & 8.9 & 0.0531 & 1.7 & 0.0659 & 0.0592 \\
\hline & $8-32$ & 9.9 & 0.0591 & 1.9 & 0.0736 & 0.0660 \\
\hline \multirow{6}{*}{9} & $9-11$ & 8.2 & 0.0490 & 1.8 & 0.0698 & 0.0584 \\
\hline & $9-12$ & 12.3 & 0.0734 & 1.7 & 0.0659 & 0.0696 \\
\hline & $9-21$ & 14.8 & 0.0884 & 1.8 & 0.0698 & 0.0785 \\
\hline & $9-22$ & 13.6 & 0.0812 & 2.0 & 0.0775 & 0.0793 \\
\hline & $9-31$ & 13.7 & 0.0818 & 2.1 & 0.0814 & 0.0816 \\
\hline & $9-32$ & 12.5 & 0.0746 & 1.9 & 0.0736 & 0.0741 \\
\hline
\end{tabular}

表6 试验结果归一化处理: 最后3组19-27试件试验统计 $\left(t_{i}=75 \%\right)$ 。

表4、表5、表6分别表示说明不同再生骨料新型混凝土 路面砖抗压强度和抗滑移强度试验结果比较。试验结果表 明在再生骨料替代率保持不变的情况下, 每组试验路面砖 抗压强度值离散型不是很大, 仅有几块试件有一定偏离, 路面砖抗滑移强度(也可称为竣工完成后的粘结底面的水 平剪切强度)较低, 约为抗压强度的 $1 / 6 \sim 1 / 4$ 。每组总功效系 数最后几项表现最大, 说明路面砖的综合性能较优; 当再 生骨料混凝土替代率较大时, 路面砖的抗压强度有明显降 低, 最大降幅达 $50 \%$, 抗滑移强度也有一定降低, 降低幅 度也很大; 当路面砖不设置板钉和板钉数量由 4 个增至 6 个 时, 路面砖的抗压强度变化不明显, 抗滑移强度也只有些 许提高, 试验结果离散性不太大, 表明板钉数量对路面砖 的抗压强度和抗滑移强度有一定的提高但不显著。

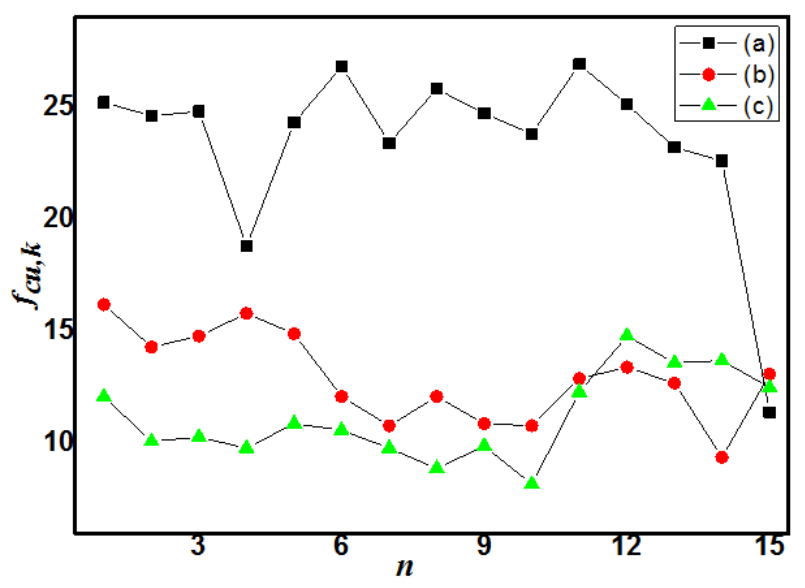

(a) 抗压强度 


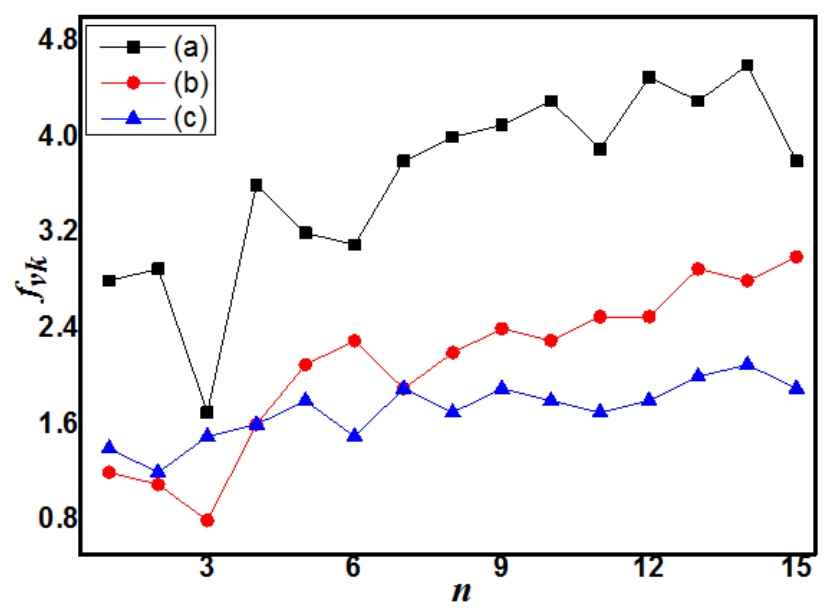

(b) 抗滑移强度

图3 试验结果分析图。

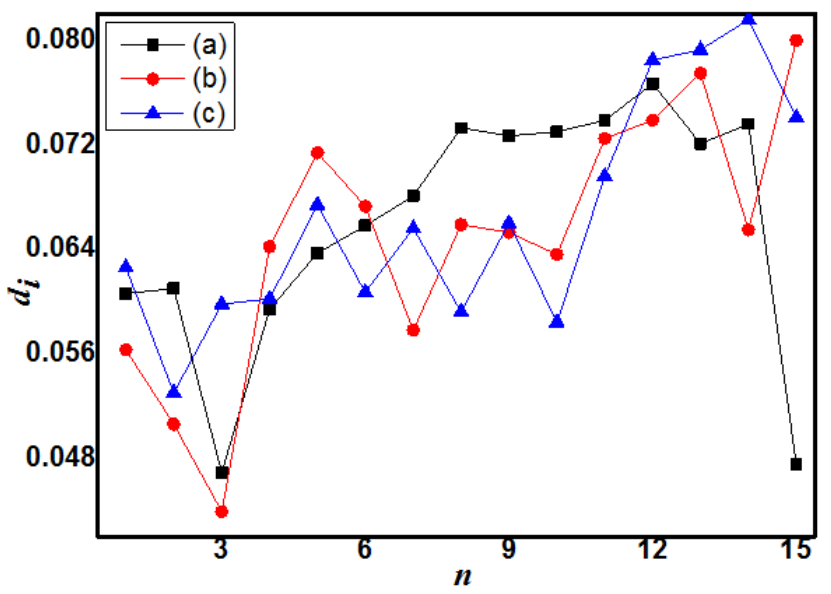

图4 试验总功效系数分析图。

图3和图4分别表示新型路面砖的抗压强度、抗滑移曲 线和试验总功效分析图形。从图 3 可以看出, 当再生骨料 替代天然骨料后, 每组试验结果离散形均不大, 混凝土路 面砖抗压强度和抗滑移强度有较大降低, 当混凝土再生骨 料替代率越多, 其降幅越大, 降幅达 $50 \%$; 从图 4 可以看 出混凝土再生骨料替代率不同时总功效系数差别不大, 表 明再生骨料制作人行道路面砖综合性能不降低, 但是充分 利用了建筑垃圾废弃物, 节约了宝贵的土地资源, 降低了 对生态环境的破坏。

\section{4. 结论}

综合前面的试验结果和分析, 本文针对建筑垃圾废 弃混凝土再生骨料, 以水灰比、再生骨料替代率为主要 参数, 主要研究再生骨料制作一种新型人行道路面砖, 主要从再生骨料替代率、板钉数量及板钉厚度三项因素 指标来分析路面砖的抗压强度和抗滑移强度二的变化关 系。分析结果表明, 当再生骨料替代天然骨料越多, 新 型路面砖的抗压强度和抗滑移强度具降低, 降幅甚至达 到 $50 \%$; 当路面砖不设板钉和设置板钉时抗压强度基本
接近, 但是设置板钉的路面砖比不设置板钉的路面砖抗 滑移强度要提高一些, 并且数量越多, 提高幅度也相应 增大; 当路面砖板钉数量一定时, 板钉厚度越大, 路面 砖的抗滑移强度虽有一定提高, 但增幅不明显; 从路面 砖的试验总功效系数来看, 应用再生混凝土设计制作新 型人行道路面砖综合性能不亚于天然骨料制作人行道路 面砖的情况，但是再生骨料充分利用了建筑垃圾固体废 弃物, 降低了环境污染, 节约了土地资源, 减少了对生 态环境的破坏, 为实现国家可持续发展, 建立资源节约 型和环境友好型社会有重要的现实意义。

本文在新型路面砖设计有 4 个板钉和 6 个板钉, 板钉 厚度分别设计为 $1 \mathrm{~mm} 、 1.5 \mathrm{~mm}$ 和 $2 \mathrm{~mm}$ 。采用正交试验, 分析不同水胶比和再生骨料替代率等因素对新型路面 砖的抗压强度和抗滑移强度的影响。试验结果显示, 每 组试验路面砖抗压强度值离散型不是很大, 仅有几块试 件有一定偏离, 路面砖抗滑移强度(也可称为竣工完成 后的粘结底面的水平剪切强度)较低, 约为抗压强度的 $1 / 6 \sim 1 / 4$ 。

在试验中, 每组总功效系数最后几项表现最大, 说明 路面砖的综合性能较优; 当再生骨料混凝土替代率较大时, 路面砖的抗压强度有明显降低, 最大降幅达 $50 \%$, 抗滑移 强度也有一定降低, 降低幅度也很大; 当路面砖不设置板 钉和板钉数量由 4 个增至 6 个时, 路面砖的抗压强度变化不 明显, 抗滑移强度也只有些许提高, 试验结果离散性不太 大, 表明板钉数量对路面砖的抗压强度和抗滑移强度有一 定的提高但不显著。

致谢

基金项目：湖南省科技计划项目（2011NK3070）

\section{参考文献}

[1] 李海明. 我国城市建筑垃圾资源化利用研究进展与展望[J]. 建筑技术，2013,44(9):795-797。

[2] 郭吴, 李英子. 北京市建筑垃圾资源化研究 [J]. 经济师, 2014,(1):21-22。

[3] 赵海英, 薛俭. 我国在建筑垃圾资源化中存在的问题及对策 研究[J]. 施工技术, 2010,(S2):472-473。

[4] 蒲云辉, 唐嘉陵. 日本建筑垃圾资源化对我国的启示 [J]. 建 筑技术，2012,41(376):43-45。

[5] 张亚梅, 秦鸿根, 孙伟等. 再生混凝土配合比设计初探 [J]. 混凝土与水泥制品, 2002,123(1):7-9。

[6] 朱平华, 谢飞飞. 再生混凝土路面砖性能研究[J]. 混凝土, 2015,(12):134-137。

[7] 何霞, 朱从香, 王兵. 再生混凝土路面砖抗碳化性能试验研 究[J]. 建筑技术, 2017,48(5):523-527。 
[8] 崔正龙, 路沙沙, 汪振双. 再生骨料特性对再生混凝土强度 和碳化性能的影响 [J]. 建筑材料学报, 2012,(4):264-267。

[9] 王江, 薛燕飞, 周辉. 再生混凝土抗压强度研究 [J]. 混凝土, 2006,(7):47-48。

[10] 周静海, 王晓天, 郭易奇, 康天蓓. 再生混凝土抗压强度的 影响因素的有限元分析[J]. 混凝土, 2017,(6):1-4。

[11] 董振平, 赵凯月, 王艳, 康天蓓. 再生塑料混凝土研究现状 [J]. 混凝土，2017,(3):100-104。

[12] 李佳涁, 肖建庄, 黄键. 再生粗骨料取代率对混凝土抗压强 度的影响 [J]. 建筑材料学报, 2006,(3):297-301。

\section{作者简介}

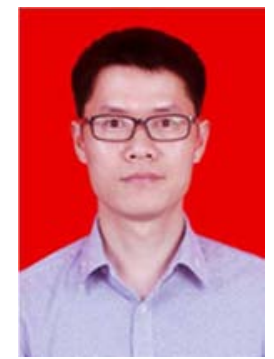

杨敬林(1978-), 男, 湖南武冈人, 硕 士, 讲师, 主要从事混凝土结构材料 研究工作。 